\title{
Long-term treatment of refractory severe chronic urticaria by omalizumab: analysis of two cases
}

\author{
Irene Fiorino ${ }^{1}$, Filomena Loconte ${ }^{1}$, Anna Simona Rucco ${ }^{1}$, Andrea Nico ${ }^{1}$, Maddalena Vacca ${ }^{1}$, Elisabetta Damiani ${ }^{1}$, \\ Eustachio Nettis ${ }^{1}$, Maria Filomena Caiaffa ${ }^{2}$, Luigi Macchia ${ }^{1}$
}

${ }^{1}$ Department and School of Allergology and Clinical Immunology, University of Bari - Aldo Moro, Bari, Italy Head of Department: Prof. Luigi Macchia MD, PhD

${ }^{2}$ Department and School of Allergology and Clinical Immunology, University of Foggia, Foggia, Italy

Head of Department: Prof. Maria Filomena Caiaffa

Postep Derm Alergol 2014; XXXI, 5: 332-334

DOI: 10.5114/pdia.2014.44023

Omalizumab is a recombinant humanized monoclonal antibody raised against the $C \varepsilon 3$ domain of human IgE, whose efficacy and safety in the treatment of moderate to severe asthma has been demonstrated [1-3]. Several other possible indications for this innovative drug have been considered, including severe idiopathic urticaria [4-6].

Here we report on two stubbornly refractory cases successfully treated with omalizumab.

Case 1. A Caucasian housewife and part-time domestic caretaker, aged 50 . Since 2002, she had been suffering from severe idiopathic urticaria. Giant, intensively itchy lesions were often (but not always) elicited by pressure.

Previous unsuccessful therapies comprised: highdose antihistamine (including ketotifen); leukotriene modifiers; dapsone; cyclosporine (4 mg/kg/day); bromazepam; and prolonged low to mid-dose corticosteroid courses.

At presentation, the patient had been treated with betamethasone (1 mg/day) for 2 years, consecutively, in association with various antihistamines at high dosage (up to 4 times the standard dosage). Moreover, she was following a rather restricted "hypo-allergic" diet. In spite of this therapeutic regimen, she was fully symptomatic, with daily eruptions of large itchy wheals, appreciable scratching lesions, and severe pruritus. The current 7-day Urticaria Activity Score (UAS) [7] was > 38. Total IgE count was $170 \mathrm{kU} / \mathrm{l}$. Other allergy and immunology tests were negative, including auto-immunity tests. However, the autologous serum test was positive (undiluted), compatible with the presence of possible autoimmune pathogenic mechanisms (e.g. autoantibodies to lgE or to the $\alpha$ chain of the high affinity IgE receptor F(cRI).

After discontinuation of the corticosteroid therapy and an additional attempt at controlling the symptoms with fexofenadine and cyproheptadine (which failed), we started the treatment with omalizumab (off-label; $300 \mathrm{mg} / \mathrm{month}$; the dose was calculated according to the standard schedule for severe asthma; body weight was $52 \mathrm{~kg})$.

The monoclonal antibody produced a dramatic and almost immediate (2 days) clinical improvement. Antihistamine therapy (fexofenadine $180 \mathrm{mg}$ daily and ketotifen $2 \mathrm{mg}$ b.i.d.) was initially needed in order to achieve full symptom control (7-day UAS $\cong 0$ ). After 9 months we decided to raise the omalizumab dosage to $450 \mathrm{mg} /$ month. That enabled discontinuation of the antihistamine therapy. As at March 2014, the patient has been under omalizumab treatment for 21 months and remains disease-free. No immediate or delayed side effects have been detected (54 single administrations given).

Case 2. Also a Caucasian housewife, 54, who had been suffering from severe idiopathic urticaria since she was 30, first episodically, then, since 2003, chronically. The 7-day UAS at presentation was 40 . The autologous serum test was positive (undiluted). Over the time, aside from high-dose non-sedating antihistamines (up to 4 times the standard dosage), therapeutic approaches had included: prolonged corticosteroid courses; sedating $\mathrm{H}_{1}$-antihistamines; $\mathrm{H}_{2}$-antihistamines; bromazepam; cyclosporine (4 mg/kg/daily; producing unsustainable side effects); methotrexate; and high-dosage mycophenolate mofetil. All these therapies had failed. Therefore, in June 2010, we started an off-label omalizumab course at the dosage of $150 \mathrm{mg} / \mathrm{month}$ (at that time, we opted for a dosage independent from total lgE measurement $(195 \mathrm{kU} / \mathrm{l})$ and body weight $(75 \mathrm{~kg}))$. Also in this case, a rapid symptom relief followed and the concomitant antihistamine therapy could be first tapered and then discontinued (7-day UAS $\cong 0$ ). The patient has been

Address for correspondence: Prof. Luigi Macchia MD, PhD, Department and School of Allergology and Clinical Immunology, University of Bari - Aldo Moro, Piazza Giulio Cesare, Policlinico, 70124 Bari, Italy, phone: +39 0805478817 , fax: +39 0805593688 , e-mail: luigi.macchia@uniba.it

Received: 30.01.2014, accepted: 29.04.2014 
essentially disease-free for 4 years, under omalizumab treatment, with a UAS value of 0 . However, we have recently decided to shorten the administration interval to 3 weeks, due to the occasional recurrence of wheals and pruritus towards the end of the previous inter-administration interval of 4 weeks.

No immediate or delayed side effects were ever noticed (49 injections administered).

Omalizumab has been regarded for some years already as a possible valuable therapeutic option for refractory severe urticaria [4-6]. Several authoritative double-blind placebo-controlled studies have been published in the last few years [8-10]. Thus, an early, phase II, dose-finding investigation showed efficacy after a single omalizumab dose of $300 \mathrm{mg}$ [8]. A more recent, phase III study investigated safety of omalizumab treatment (300 mg, every 4 weeks, for 24 weeks) in patients with chronic idiopathic urticaria resistant to $\mathrm{H}_{1}$-antihistamines at up to 4 times the approved dose plus $\mathrm{H}_{2}$-antihistamines and leukotriene antagonists. Along with an excellent safety profile, this study also showed that omalizumab was robustly efficacious [9]. Another phase III study was carried out in patients who remained symptomatic in spite of $\mathrm{H}_{1}$-antihistamines at licensed doses. The patients received 3 injections of omalizumab, spaced 4 weeks apart, at doses of $75 \mathrm{mg}, 150 \mathrm{mg}$, and $300 \mathrm{mg}$ or placebo. The study showed a significant improvement in patients receiving $150 \mathrm{mg}$ or $300 \mathrm{mg}$ of omalizumab (but not $75 \mathrm{mg}$ ), as compared with placebo [10].

Moreover, several cases of off-label treatment, including case reports and small and middle-sized series [11-14] have been published.

Taken together, this literature indicates that this novel approach is more than realistic and feasible.

However, many aspects of the problem remain to be assessed, as epitomized by the fact that, so far, omalizumab has not been approved for urticaria (of any kinds), worldwide. In particular, retrospective studies, conducted in real-life settings $[15,16]$, have started to address such important issues as treatment duration, long-term efficacy and safety, dose adjustment, and others.

In this context, we believe that these two additional cases, managed for prolonged periods of time, are likely to provide further noteworthy information, which can be synthesized as follows: Omalizumab was effective, enabling achievement of complete control in these stubbornly recalcitrant cases, characterized by severe symptoms lasting for many years and resistant to virtually all known treatments. The relief afforded was impressively fast, as reported also by others [15]. This may suggest that omalizumab efficacy might be investigated also in the case of aggressive, treatment-resistant acute urticaria, perhaps with a single administration followed by conventional therapy. It seemed that the dosage had to be determined empirically (rather than rigidly based on total IgE levels and body weight, as for severe asthma) and, perhaps, adjusted, from time to time, in order to achieve and maintain full disease control, as recently suggested [16]. Prolonged treatment did not seem to cause a decline in efficacy. On the other hand, it appeared that omalizumab should be given for very long periods of time, if not indefinitely, in cases such as those presented [9]. The safety profile was excellent, since neither immediate nor delayed side effects of any kinds were recorded, over many months. Finally, lack of omalizumab approval for this specific indication by regulatory boards precludes a wider and probably highly beneficial employment of omalizumab in patients with severe chronic urticaria, which, in our opinion, would lead to a net reduction in both the human and the social and economic burden of this disease.

The study was approved by the Ethics Committee of one of the two Institutions involved (University of Foggia) and complies with the provisions of the Declaration of Helsinki (and subsequent amendments). Informed consent was granted by the two participants.

\section{References}

1. Holgate ST, Chuchalin AG, Hébert J, et al. Efficacy and safety of a recombinant anti-immunoglobulin $\mathrm{E}$ antibody (omalizumab) in severe allergic asthma. Clin Exp Allergy 2004; 34: 632-8.

2. Cazzola M, Camiciottoli G, Bonavia M, et al. Italian real-life experience of omalizumab. Respir Med 2010; 104: 1410-6.

3. Kourtis G, Rucco AS, Loconte F, et al. Omalizumab in severe allergic asthma: efficacy assessment by comparison of symptom score and peak expiratory flow values before and after therapy. J Investig Allergol Clin Immunol 2010; 20: 451-2.

4. Kaplan AP, Joseph K, Maykut RJ, et al. Treatment of chronic autoimmune urticaria with omalizumab. J Allergy Clin Immunol 2008; 122: 569-73.

5. Zuberbier T, Asero R, Bindslev-Jensen C, et al. EAACl/GA(2) LEN/EDF/WAO guideline: management of urticaria. Allergy 2009; 64: 1427-43.

6. Maurer M, Magerl M, Metz M, Zuberbier T. Revisions to the international guidelines on the diagnosis and therapy of chronic urticaria. J Dtsch Dermatol Ges 2013; doi: 10.1111/ ddg.12194.

7. Zuberbier T, Asero R, Bindslev-Jensen C, et al. EAACI/GA(2) LEN/EDF/WAO guideline: definition, classification and diagnosis of urticaria. Allergy 2009; 64: 1417-26.

8. Saini S, Rosen KE, Hsieh HJ, et al. A randomized, placebo-controlled, dose-ranging study of single-dose omalizumab in patients with $\mathrm{H1}$-antihistamine-refractory chronic idiopathic urticaria. J Allergy Clin Immunol 2011; 128: 567-73.

9. Kaplan A, Ledford D, Ashby M, et al. Omalizumab in patients with symptomatic chronic idiopathic/spontaneous urticaria despite standard combination therapy. J Allergy Clin Immunol 2013; 132: 101-9.

10. Maurer M, Rosén K, Hsieh HJ, et al. Omalizumab for the treatment of chronic idiopathic or spontaneous urticaria. N Engl I Med 2013; 368: 924-35.

11. Ivyanskiy I, Sand C, Thomsen SF. Omalizumab for chronic urticaria: a case series and overview of the literature. Case Rep Dermatol 2012; 4: 19-26. 
12. Metz M, Maurer M. Omalizumab in chronic urticaria. Curr Opin Allergy Clin Immunol 2012; 12: 406-11.

13. Armengot-Carbo M, Velasco-Pastor M, Rodrigo-Nicolas B, et al. Omalizumab in chronic urticaria: a retrospective series of 15 cases. Dermatol Ther 2013; 26: 257-9.

14. Lefévre AC, Deleuran M, Vestergaard C. A long term case series study of the effect of omalizumab on chronic spontaneous urticaria. Ann Dermatol 2013; 25: 242-5.

15. Metz M, Ohanyan T, Church MK, Maurer M. Omalizumab is an effective and rapidly acting therapy in difficult-to-treat chronic urticaria: a retrospective clinical analysis. J Dermatol Sci 2014; 73: 57-62.

16. Uysal P, Eller E, Mortz CG, Bindslev-Jensen C. An algorithm for treating chronic urticaria with omalizumab: dose interval should be individualized. J Allergy Clin Immunol 2013; 133 : 914-5. 